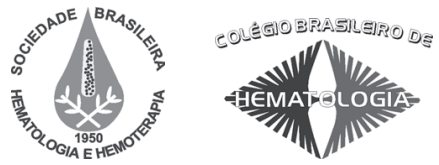

\title{
Augusto Luiz Gonzaga Augusto Luiz Gonzaga
}

Milton A. Ruiz

Faleceu recentemente Augusto Luiz Gonzaga. Foi vicepresidente da Sociedade Brasileira de Hematologia e Hemoterapia (SBHH) de 1983 a 1985 e presidente do biênio de 1985 -1987. Polêmico, contestador, visionário, centralizador, estes eram alguns dos adjetivos a ele atribuídos em sua época de atividades na Hematologia e Hemoterapia brasileira. Fundador do Centro de Hematologia Santa Catarina, no Rio de Janeiro militou intensamente na área de coagulação e hemostasia e foi o grande incentivador da organização das Casas dos Hemofílicos. A sua participação no CLAHT (Grupo Latino Americano de Hemostasia e Trombose) e WFH (Confederação Mundial de Hemofilia) foram relevantes, organizando eventos e aproximando a SBHH destes organismos internacionais. Em 1985 organizou o Congresso Mundial de Hemofilia no Rio de Janeiro em conjunto com o Congresso Brasileiro de Hematologia, prática que se disseminou posteriormente no seio da Sociedade Brasileira de Hematologia e Hemoterapia.

Afastado das lides hematológicas, há mais de 10 anos, desde o início contribuiu com o Boletim, sendo o responsável pela coluna "Clube do Anticorpo" e da edição de diversas contribuições. Foi o mentor principal da transformação daquele veículo de comunicação em revista, inclusive prestando decisivo apoio financeiro para a sua edição, que era mensal. Fazia juz a todos os adjetivos e dele, dentre outras coisas, me recordo quando, como presidente, disse: "Faça uma revista como o New England Journal of Medicine. Não precisa ser tão boa, basta que publique tudo dos brasileiros. Você verá, as máquinas de escrever vão desaparecer e a revista vai continuar". Foi assim que circulou, em Buenos Aires, no Congresso Internacional de Hematologia, de 1984, o primeiro fascículo do Boletim da Sociedade Brasileira de Hematologia e Hemoterapia embrião da atual Revista Brasileira de Hematologia e Hemoterapia. E a capa da revista? Parecida com a sugestão.

Recebido: $24 / 03 / 2009$

Aceito: 24/03/2009

Faculdade de Medicina da USP - São Paulo-SP.

Editor da Revista Brasileira de Hematologia e Hemoterapia.

Correspondência: Milton Artur Ruiz

Av. Dr. Enéas Carvalho de Aguiar, 144 - Cerqueira César

05403-000 - São Paulo-SP - Brasil

E-mail: milruiz@yahoo.com.br 